\title{
Extracapsular cataract extraction under local anaesthesia without retrobulbar injection
}

\author{
R M Redmond, N L Dallas
}

\begin{abstract}
Day-case cataract surgery and the need for local anaesthesia are likely to increase. Retrobulbar (and peribulbar) anaesthetic injection is a common technique in cataract surgery, but serious complications are persistently reported. Subconjunctival injection is an alternative that avoids these risks. This retrospective study compares two groups of patients that underwent extracapsular cataract surgery under local anaesthetic. One group (retrobulbar) had uncomplicated retrobulbar injection with bupivicaine and hyaluronidase. The other group (non-retrobulbar) had superior bulbar, subconjunctival infiltration with bupivicaine and hyaluronidase. The operative complications and postoperative visual outcomes were similar in both groups. These results may encourage the investigation and adoption of the subconjunctival alternative to retrobulbar anaesthetic injection in cataract surgery.
\end{abstract}

A recent editorial ${ }^{1}$ advocated the use of subconjunctival infiltration in preference to retrobulbar injection for local anaesthesia in cataract extraction. The well recognised risks of retrobulbar injection include a $1 \%$ to $3 \%$ risk of retrobulbar haemorrhage, ${ }^{2}$ perforation of the globe, ${ }^{3}$ embolism of the central retinal artery, ${ }^{2}$ and injection into the subarachnoid space. ${ }^{4}$ Cardiac arrest, respiratory arrest, and seizures have been reported following retrobulbar injection..$^{5-7}$ This form of anaesthesia does not guarantee absolute ocular akinesia, ${ }^{8}$ while the risks remain despite widely advocated changes in technique. ${ }^{9}$ These risks can be avoided with subconjunctival infiltration. This alternative to retrobulbar injection was used for non-implantation, intracapsular surgery by individual surgeons in Glasgow over 20 years ago (Chisholm I A, personal communication). It is probable that the more recent introduction of hyaluronidase has improved its efficacy, and several registrars at the Bristol Eye Hospital have used non-retrobulbar local anaesthesia over the past five years. Nevertheless, the technique is not widely practised, and the suspicion remains that inadequate ocular akinesia results.

This retrospective report compares two groups of patients in whom extracapsular cataract surgery and lens implantation were performed under local anaesthesia. One group had retrobulbar anaesthesia, while the other did not. The patients were operated on by one registar only (RMR), and the distribution of types of anaesthesia used by the surgeon over the two-year period of the study is shown in Figure 1.

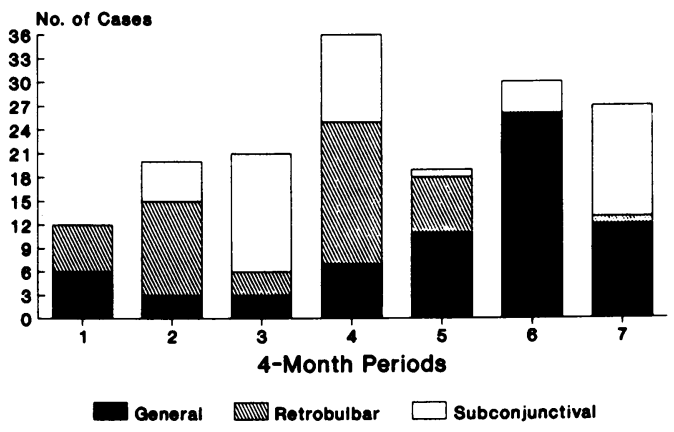

Figure 1: Distribution of general, retrobulbar, and subconjunctival anaesthetic cases during the study period.

\section{Patients and methods}

Two groups, each of 50 Caucasian patients, are reported on. There were no significant differences in mean age (Table I) or male/female ratio between the two groups.

Patients in the retrobulbar group had topical benoxinate (Minims), an O'Brien facial block (supplemented when necessary with a van Lint procedure), and a retrobulbar injection (1.5$2 \mathrm{ml}$ ) through the lower lid with the eye in downgaze after puncture of the rectus cone. Patients in the non-retrobulbar group had a similar facial nerve and topical block. With the eye in downgaze and the upper lid retracted by the surgeon's thumb, a 23 gauge needle was used to infiltrate under the superior bulbar conjunctiva (approximately $1 \mathrm{ml}$ ), raising a bleb that extends from the superior limbus to beyond the insertion of the superior rectus tendon. $0.5 \%$ plain bupivicaine (Marcaine) with 1500 units of hyaluronidase was used for all injections.

Cases of retrobulbar haemorrhage which occurred in this two-year period have been excluded from this report and are not listed as complications in Table II. Far larger case series have already established the approximate risk of retrobulbar haemorrhage following injection.

Extracapsular cataract extraction under an operating microscope was standardised, with a

TABLE I Mean age and age range of patients in retrobulbar and non-retrobulbar groups

\begin{tabular}{lll}
\hline & $\begin{array}{l}\text { Retrobulbar } \\
(n=50)\end{array}$ & $\begin{array}{l}\text { Non-retrobulbar } \\
(n=50)\end{array}$ \\
\hline Age: & $\begin{array}{l}\text { Mean }=77 \cdot 1 \mathrm{yr} \\
\text { Range }=57-96 \mathrm{yr}\end{array}$ & $\begin{array}{l}\text { Mean }=76 \cdot 1 \mathrm{yr} \\
\text { Range }=62-94 \mathrm{yr}\end{array}$ \\
\hline
\end{tabular}

TABLE II Peroperative and early postoperative complications

\begin{tabular}{|c|c|c|c|}
\hline & $\begin{array}{l}\text { Retrobulbar } \\
(n=50)\end{array}$ & & $\begin{array}{l}\text { Non-retrobulbar } \\
(n=50)\end{array}$ \\
\hline & $\begin{array}{l}\text { Mean }=2 \cdot 5 \text { DC } \\
\text { Range }=0 \cdot 25-5\end{array}$ & & $\begin{array}{l}\text { Mean }=2.5 \mathrm{DC} \\
\text { Range }=1-4.5\end{array}$ \\
\hline $\begin{array}{l}\text { Complications } \\
\text { (eyes): }\end{array}$ & $\begin{array}{l}\text { Vitreous loss } \\
\text { Iris prolapse } \\
\text { Wound leak }\end{array}$ & $\begin{array}{l}3 \\
1 \\
2\end{array}$ & $\begin{array}{ll}\text { Vitreous loss } & 2 \\
\text { Residual cortex } & 2\end{array}$ \\
\hline
\end{tabular}

Grosvenor Road, Belfast R M Redmond

Bristol

N L Dallas

Correspondence to: $\mathrm{Mr} \mathrm{R} M$ Redmond.

Accepted for publication

13 October 1989 
Figure 2: Preoperative visual acuity in retrobulbar and subconjunctival cataract extraction cases.

Rotrobulbar

Sultw Sub.conj. injection

Figure 3: Postoperative visual acuity in retrobulbar and subconjunctival cataract extraction cases.

Rotrobulbar

ब⿴囗十ा Subconj. injection
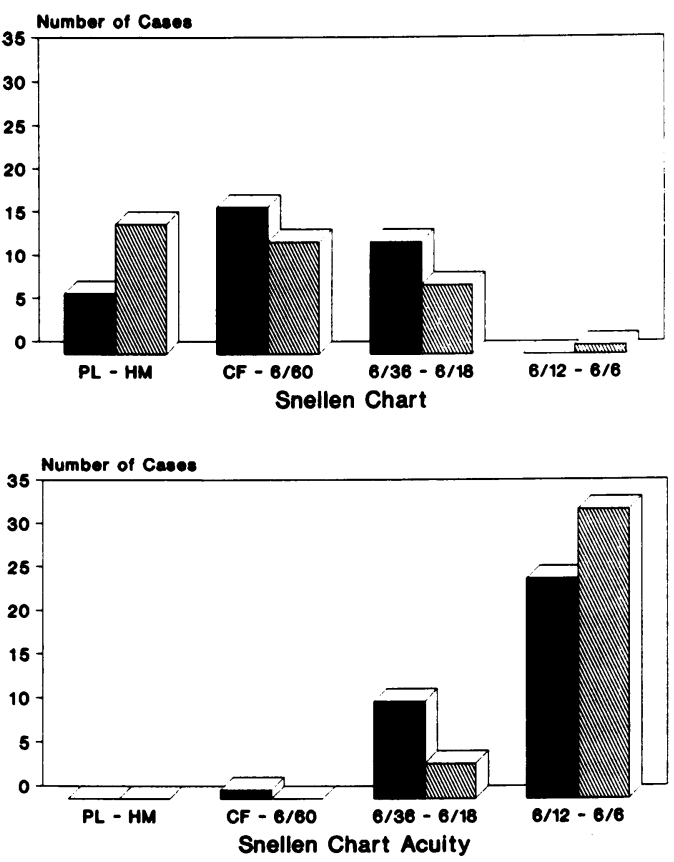

superior rectus fixation suture, a fornix-based conjunctival flap, and a circular 'can opener' anterior capsulotomy performed in all cases. Lens nuclei were expressed rather than delivered with a Vectis and aspiration of residual cortex was either manual (McIntyre or Simcoe) or automated (Empac or Cavitron). In most cases the incision was closed with five interrupted stitches of 10/0 Prolene or nylon.

\section{Results}

The final outcome was assessed in terms of improvement of visual acuity and the complication rate.

There was no difference in improvement of visual acuity between retrobulbar and nonretrobulbar groups, the mean improvement being from Snellen 6/60 to 6/9 (Figs 2, 3). Cases in which vision did not improve owing to previously unrecognised macular or optic nerve pathology have been excluded from the analysis of visual acuity. No significant difference was found in postoperative astigmatism between the two groups (retrobulbar, mean cyl=2.5 D; nonretrobulbar, mean cyl $=2.5 \mathrm{D}$ ).

The frequency of peroperative and early postoperative complications for the two groups is shown in Table II. There were three cases of vitreous loss in the retrobulbar group and two in the non-retrobulbar group. All cases of vitreous loss occurred early in the two-year study period and were attributable to accidental rupture of the posterior capsule during cortex aspiration.

Scrutiny of the comments on operation sheets in all cases did not reveal a greater incidence of problematic ocular motility in the nonretrobulbar group. For three cases in this group there was a comment that the globe was convergent throughout the operation. Surprisingly, no patient in the non-retrobulbar group complained about the bright light of the operating microscope. In these cases it is unlikely that the optic nerve is 'blocked', especially early in the course of the operation.

The surgeon's subjective opinion was that retrobulbar injection tended to cause more distress for the patient than subconjunctival bupivicaine, and that peroperative anaesthesia was adequate in both study groups.

\section{Discussion}

General anaesthesia is regarded by most ophthalmic surgeons as being the ideal for extracapsular cataract extraction. Carbon dioxide monitoring enables safe hyperventilation of the patient with a relative collapse of the vitreous body and deepening of the posterior chamber. In addition ocular akinesia is assured. Local anaesthesia does not have these advantages. Nevertheless local anaesthesia is widely used in the UK and is occasionally requested by the patient. Day-case surgery may become commoner in future, with an attendant increase in local anaesthetic cases.

The complications of retrobulbar injection have been listed above. It is conceivable that an intraconal retrobulbar injection might increase orbital tension and forward bulging of the vitreous, particularly if a small and undetected intraconal haemorrhage occurs. Subconjunctival infiltration will not have this effect. However, it might be feared that greater rectus tone and greater ocular motility without retrobulbar anaesthesia could heighten the risk of vitreous loss or of endothelial cell damage. These later fears were not borne out in this study.

Adequate ocular akinesia with only a subconjunctival injection of bupivicaine $0.5 \%$ and hyaluronidase is perhaps surprising. The anaesthetic rapidly diffuses to the superior rectus and the horizontal recti muscles. Intraconal diffusion is possible, but it is likely to be delayed and to represent only a small proportion of the original volume of anaesthetic. The superior rectus bridle suture is an important factor in steadying the globe in the vertical plane, and the use of a 'one-handed' automated irrigation/aspiration system enables the edge of the section to be gripped with microforceps during cortex aspiration. Any residual movement is usually slight and in the horizontal plane, so that the surgeon can easily compensate for it.

This retrospective study supports the suggestion that consistently good results from extracapsular cataract extraction can be obtained without the use of retrobulbar anaesthesic injection.

We thank Mr P B Johnston for his advice and encouragement during the preparation of this paper.

1 Smith RJH. Editorial: Why retrobulbar anaesthesia? $\mathrm{Br} \mathcal{f}$ Ophthalmol 1988; 72: 1

2 Morgan CM, Schatz H, Vine AK, et al. Ocular complications associated with retrobulbar injections. Ophthalmology 1988 ; 95: $660-5$.

3 Ramsay RC. Ocular perforation following retrobulbar anaesthesia for retinal detachment surgery. Am $\mathcal{f}$ Ophthalmol 1978;

4 Javitt JC, Addiego R, Friedberg HL, Libonati MM, Leahy JJ. Brainstem anaesthesia after retrobulbar block. Ophthal-
mology 1987; 94: 718-23.

5 Meyers EF. Grand mal seizures after a retrobulbar block. Arch Ophthalmol 1978; 962847 .

6 Wittpenn JR. Respiratory arrest following retrobulbar anaesthesia. Ophthalmology 1986; 93: 867-70.

McGalliard JN. Respiratory arrest after two retrobular injections. Am $\mathcal{F}$ Ophthalmol 1988; 105: 90-1.

8 Abelson MB. The effect of hyaluronidase on akinesia during

cataract surgery. Ophthalmic Surg 1989; 20: 325-6.
9 McCrary JA. Discussion in: Javitt JC, Addiego R, Friedberg Crary JA. Discussion in: Javitt JC, Addiego R, Friedberg retrobulbar block. Ophthalmology Vol 94 1987; 94: 718-23. 